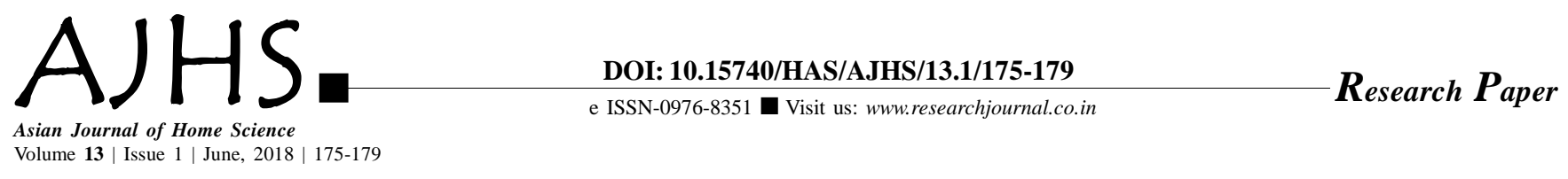

\title{
Development of silk Kurtis with tie and dye technique using natural dyes
}

Arpana Kamboj and Surabhi Mahajan

Received: 26.12.2017; Revised: 01.04.2018; Accepted: 19.04.2018

See end of the paper for authors' affiliations

\section{Arpana Kamboj}

Department of Apparel and

Textile Science, Punjab

Agricultural University, Ludhiana

(Punjab) India
-ABSTRACT : Natural dyes are colouring substances that are obtained from plants, animals, insects and minerals. Their usage has seen a sharp decline because of easy availability of synthetic dyed products at an affordable price in the market. Even if consumers are willing to buy natural dyed products as a part of their social responsibility towards environment, availability of contemporary apparel products dyed with these sustainable dyes and having unique design features have to be strengthened. The present study is an attempt in this direction and aims at developing silk Kurtis with tie and dye technique using natural dyes. Five natural dyes and tannic acid mordant were purposively selected for the study. The selected dyes were Arjun, Golden drop, Kilmora, Brahmi and Madder. Eighteen designs for silk Kurtis were made by the investigator using CAD with combination of different style features and placement of tie and dye patterns. These designs were evaluated by a panel of ten experts on basis of overall appeal of the Kurti. The shortlisted six kurti designs were constructed using silk fabric and were shown to a sample of forty five respondents. All the respondents ranked the prepared Kurtis as excellent or very good and considered the estimated price of Kurtis as adequate. Thus, the consumer acceptance of the prepared Kurtis is an indication for the retailers and manufacturers to take up natural dyes for contemporary to earn good profit and run a sustainable enterprise.

KEY WORDS: Contemporary, Kurti, Quoted price, Sustainable

- HOW TO CITE THIS PAPER : Kamboj, Arpana and Mahajan, Surabhi (2018). Development of silk Kurtis with tie and dye technique using natural dyes. Asian J. Home Sci., 13 (1) : 175-179, DOI: 10.15740/ HAS/AJHS/13.1/175-179. Copyright@ 2018: Hind Agri-Horticultural Society. 